\title{
Changing mortality patterns in East and West Germany and Poland. I: Long term trends (1960-1997)
}

\author{
Ellen Nolte, Vladimir Shkolnikov, Martin McKee
}

\begin{abstract}
Objectives-To examine the long term evolution of mortality in the former German Democratic Republic (GDR) in the period from 1960 and its specific position in health terms compared with the Federal Republic (FRG) in the west and Poland in the east.

Methods-Decomposition of life expectancy by age and cause of death. Differences in life expectancy at birth between the former GDR and the old FRG were decomposed by age using data on all cause mortality for the period 1960 to 1997. Changes in life expectancy over time by cause of death were examined using data for 1974 and 1989 for both parts of Germany and for 1974 and 1988 for Poland.

Results-Male life expectancy in the two parts of Germany diverged twice, in the mid-1960s, favouring the GDR, and in the mid-1970s, giving increasing advantage to the FRG, while female life expectancy remained similar until the mid-1970s and began to diverge thereafter. The initial advantage of the GDR was mainly attributable to an improving mortality rate among children compared with that in the west in both sexes. During the 1980 s, mortality among men over 15 and women over 40 steadily worsened relative to their western counterparts, although men were doing considerably better than those in Poland who actually experienced deterioration. In the FRG, falling death rates among adults of all ages have contributed substantially to the improvement in life expectancy between 1974 and 1989 , largely attributable to falling deaths from cardiovascular disease and from injuries at younger adult ages. In Poland, death rates among male adults have risen at all ages over 35 , mostly attrib-
\end{abstract}

Accepted for publication 3 April 2000

Table 1 Life expectancy at birth in East and West Germany, Sweden and Poland since 1960 (in years)

\begin{tabular}{|c|c|c|c|c|c|c|}
\hline \multirow[b]{2}{*}{ Country } & \multicolumn{6}{|l|}{ Year } \\
\hline & 1960 & 1970 & 1980 & $1989(88)^{*}$ & $1990(91)^{*}$ & $1995-97 \dagger$ \\
\hline & Males & & & & & \\
\hline E Germany & 66.45 & 68.16 & 68.70 & 70.16 & 69.23 & 72.41 \\
\hline W Germany & 66.41 & 67.28 & 69.91 & 72.58 & 72.72 & 74.49 \\
\hline Poland & 65.98 & 66.47 & 66.11 & 67.13 & 66.14 & 68.14 \\
\hline Sweden & $\begin{array}{l}71.03 \\
\text { Females }\end{array}$ & 72.04 & 72.59 & 74.60 & 74.7 & 75.96 \\
\hline E Germany & 71.42 & 73.36 & 74.64 & 76.40 & 76.31 & 79.65 \\
\hline W Germany & 71.84 & 73.63 & 76.71 & 79.09 & 79.12 & 80.61 \\
\hline Poland & 70.50 & 73.05 & 74.60 & 75.68 & 75.36 & 76.59 \\
\hline Sweden & 74.67 & 77.00 & 78.65 & 80.37 & 80.19 & 81.23 \\
\hline
\end{tabular}

^Poland: 1988 and 1991. †Sweden: 1995, Poland: 1996, East and West Germany: 1997. utable to worsening death rates from cardiovascular disease and neoplasms while women experienced stagnation. The GDR showed a small worsening among men under 60 , counterbalanced by improvements among those over 60 , and some improvement in women, attributable to falling deaths from cardiovascular disease among the middle aged and elderly.

Conclusions-This study provides further evidence for the complexity of the eastwest mortality differential emerging in the 1960s in Europe, highlighting the intermediate position in health terms the former GDR occupied during much of the communist period. Further research is required to assess the underlying causes for the specific position of the former GDR between east and west.

(F Epidemiol Community Health 2000;54:890-898)

During the 1970s and 1980s, life expectancy at birth in central and eastern Europe stagnated. This figure, however, concealed increasing mortality in the young and middle aged, only counterbalanced by improving infant mortality. ${ }^{12}$ Since 1990, countries have followed differing paths. In Poland and the Czech Republic, life expectancy improved almost immediately, soon followed by Hungary ${ }^{3}$ while Romania and Bulgaria remained stagnant. The former German Democratic Republic (GDR) has received rather less attention. United with the Federal Republic of Germany (FRG) in 1990 the most accessible source of data, the World Health Organisation's (WHO) "Health for All" database no longer distinguishes the territory of the former GDR. Changes in mortality there have thus become relatively less visible.

Health in the former GDR is of interest for several reasons. Firstly, uniquely in the former Soviet bloc, it was rapidly absorbed into western Europe, experiencing much more rapid social and economic transition than neighbouring countries. The West German health care system was introduced rapidly. ${ }^{5}$ Secondly, before 1990, its life expectancy trends differed from those in other socialist countries and, in the early 1970s, male life expectancy at birth actually exceeded that of the FRG. ${ }^{6}$ Thirdly, it has so far attracted relatively little research, in part because detailed cause specific mortality data were suppressed during much of the communist period. 

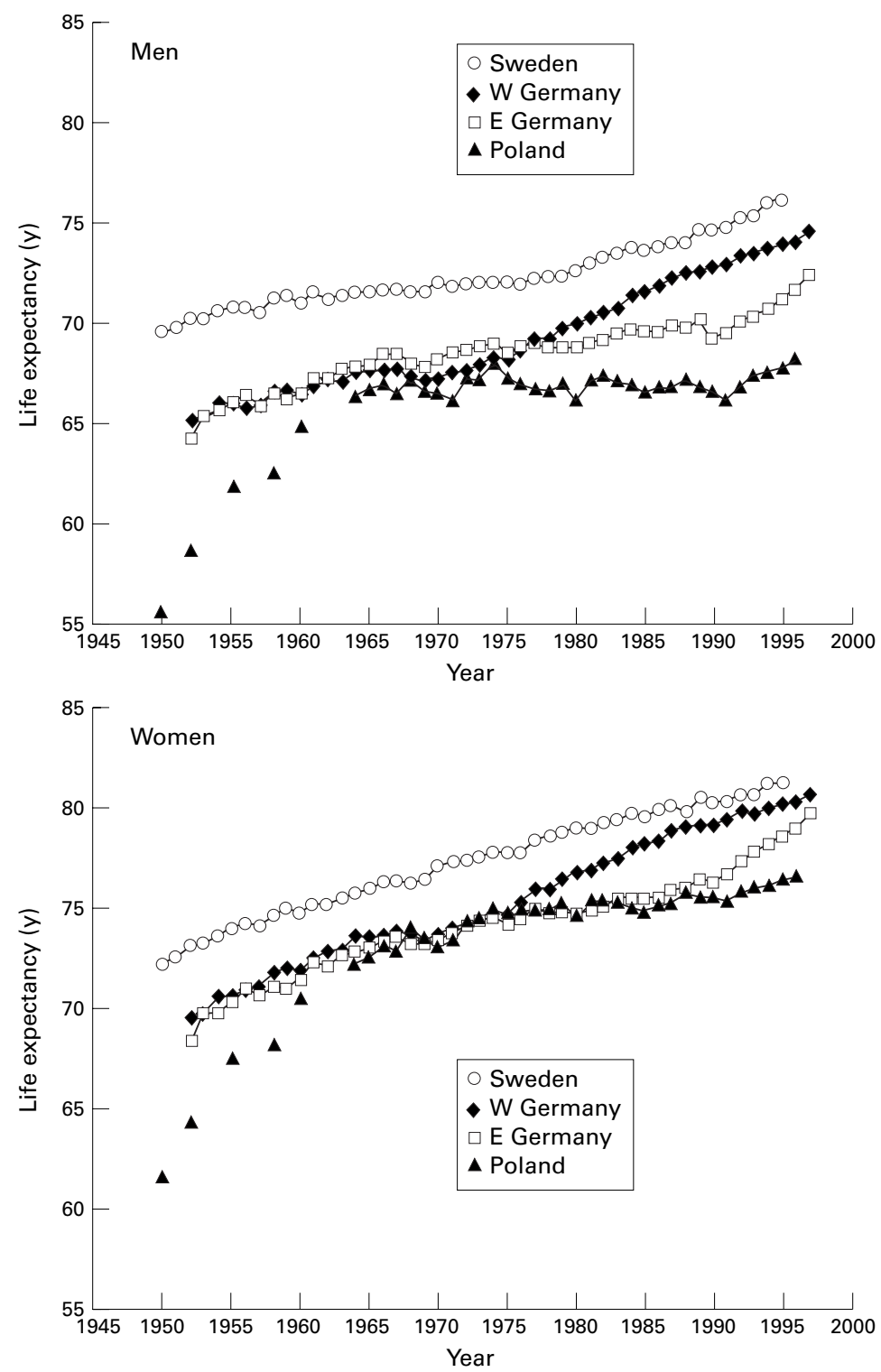

Figure 1 Life expectancy at birth in East and West Germany, Sweden, and Poland since 1950.

We have previously reported the contribution of specific causes of death to the gap in life expectancy between the two Germanys at unification. ${ }^{8}$ In this paper, the first of two linked studies, we extend this work, reporting the evolution of mortality in the former GDR from 1960. In particular, we examine how it differed from its two neighbours, the FRG and Poland. Data from Sweden, a country with one of the longest life expectancies throughout this period, are included for comparison. A second paper will examine changes since unification.

\section{Methods}

DATA

Mortality data for 1952 to 1961 (FRG) and 1968 (GDR) were obtained from the United Nations Demographic Yearbook ${ }^{9}$ and the GDR Statistical Yearbook, respectively. ${ }^{10}$ For subsequent years, data were obtained from the WHO mortality files $(1962 / 68-1990)^{11}$ and the Statistical Office Germany (1990-1997). ${ }^{12}$ Ad- ditional data were obtained from the WHO mortality files for Sweden (1950-1995) and Poland (1950-1996). Data include deaths in each year, using successive versions of the International Classification of Diseases (ICD) (WHO: abbreviated list; Statistical Office: detailed list), by sex and five year age band (with infant deaths listed separately). Data on cause of death in the GDR, however, remain incomplete from 1975 to 1988 as deaths from some violent and alcohol related causes were not reported for political reasons ${ }^{13}{ }^{14}$ but were combined with ill defined causes to maintain total all cause mortality. A similar procedure was used in the Soviet Union. ${ }^{15}$ In addition, before 1962, data for Saarland and West Berlin were excluded from FRG data supplied to WHO. To ensure continuity, these data were obtained from the historical supplement of the UN Demographic Yearbook. ${ }^{9}$

ANALYSES

We examine trends in life expectancy at birth and age specific patterns of mortality in the GDR and its neighbours, concentrating on why the GDR occupied a favourable position to the FRG around 1970, on the crossover in mid1970s, and on the widening gap between the former GDR (and Poland) and the old FRG in the 1980s. The analyses decompose life expectancy by age and cause of death. This enables separation of differences between life expectancies into contributions according to age and cause of death, expressed in years gained or lost.

Differences in life expectancy between the GDR and FRG were decomposed by age using all cause mortality data for 1960 to 1997. A further decomposition of changes in life expectancy by cause of death was performed for 1974 (the last year when information on causes of death in the former GDR was reported completely and when male life expectancy in the GDR exceeded that in the FRG) and 1989 (the first year the GDR resumed complete reporting cause specific mortality and a time when life expectancy lagged behind the west). A similar analysis was undertaken for Poland for 1974 and 1988.

Causes of death were aggregated into eight broad classes: infectious and parasitic diseases, neoplasms, circulatory diseases, respiratory diseases, digestive diseases, other diseases, ill defined conditions, and accidents and violence.

Life expectancy was calculated using standard life table techniques. ${ }^{16}$ Decomposition of differences in life expectancy was undertaken using methods developed independently by Andreev, ${ }^{17}$ Arriaga, ${ }^{18}$ and Pressat. ${ }^{19}$ Analyses used Microsoft Excel. ${ }^{20}$

Throughout this paper, East Germany refers to the territory of the former GDR before unification, including East Berlin. West Germany refers to the territory of the FRG before unification, including West Berlin.

\section{Results}

LONG TERM TRENDS IN LIFE EXPECTANCY AT BIRTH

Trends in life expectancy at birth in the two parts of Germany, Poland and Sweden, are 
shown in figure 1, with absolute values in selected years in table 1. Life expectancy in Sweden has been consistently higher than in the other countries although, since the mid1970s, the FRG began to close the gap. Life expectancy in the two parts of Germany was initially almost identical, and considerably higher than in Poland, which experienced a steep increase until the 1960s. In the early 1960 s, when the GDR was isolated from the west, male life expectancy in the GDR slowly improved while the west lagged behind. By the mid-1970s this reversed and life expectancy in the FRG moved progressively ahead until unification. Although male life expectancy in the GDR fell further behind the west, it was slowly improving and substantially higher than in Poland, which experienced stagnation.
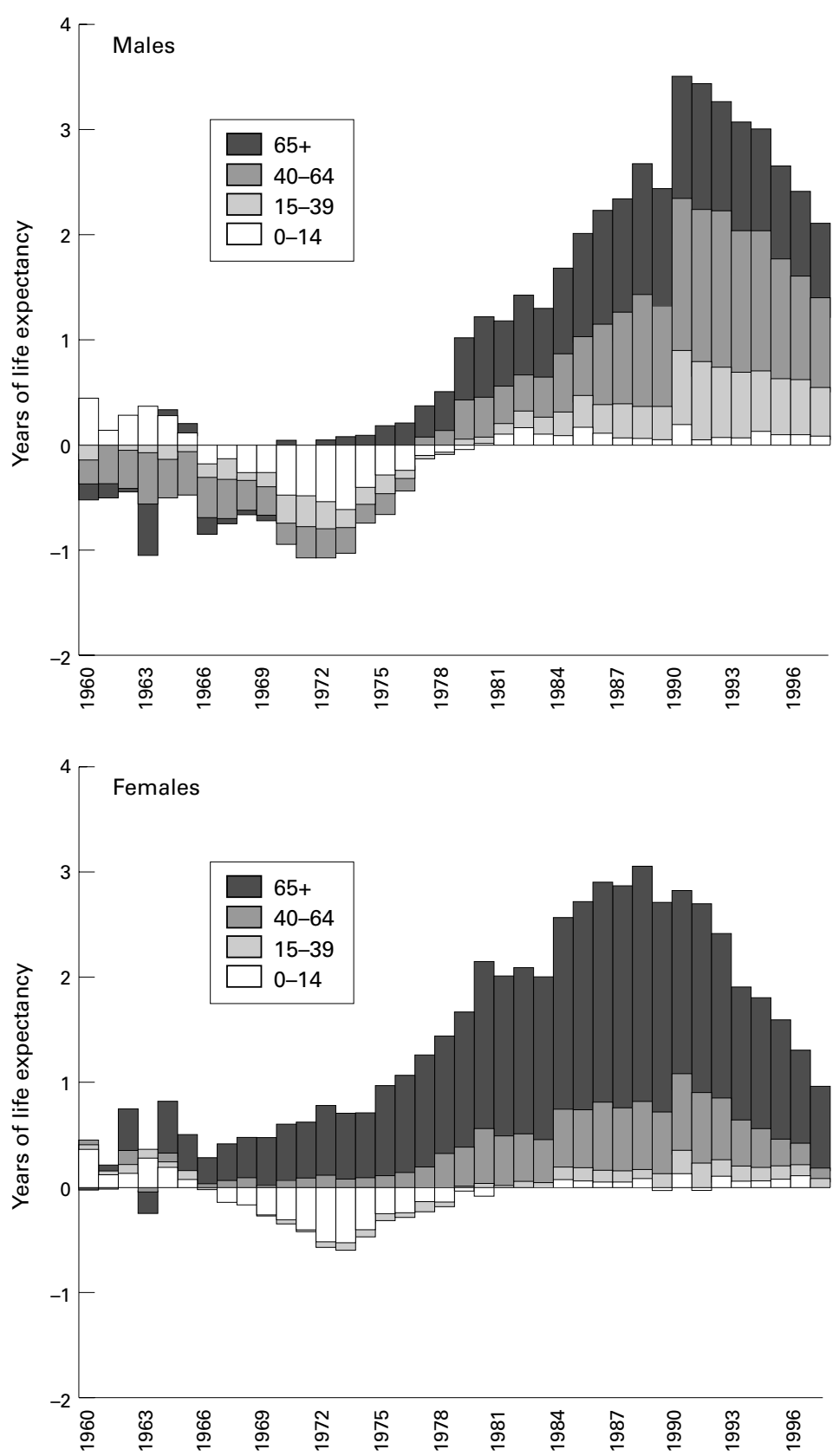

Figure 2 Age specific contribution to the overall gap in life expectancy at birth between East Germany and West Germany.
Female life expectancy in both parts of Germany remained similar until the mid-1970s, subsequently diverged, with the GDR following a trajectory similar to Poland. It did, however, improve in the late 1980s, several years before the collapse of the regime. No change occurred in Poland at that time.

After worsening briefly at the end of the 1980s, coinciding with political and economic transition, life expectancy improved considerably in the former GDR and Poland during the 1990s (table 1). By the mid-1990s, the gap between the two parts of Germany had narrowed, whereas Poland, despite some improvements, continued to lag behind (fig 1).

Figure 2 shows the contribution of deaths at different ages to the changing gap in life expectancy between the two Germanys over time. The sum of values, negative and positive, represents the gap in life expectancy at birth in years. Bars extending below the horizontal axis indicate that mortality rates in the age group concerned advantaged the GDR while bars above the axis indicate that mortality rates in an age group advantaged the FRG.

Until the mid-1970s, mortality among male adults was lower in the GDR, only counterbalanced by higher death rates among children in the 1960s. The overall advantage enjoyed by the GDR from mid-1960s to mid-1970s was attributable to steady improvement in mortality among children compared with the FRG, persisting until 1978. There was also an increasing gap in mortality among the elderly that disadvantaged the GDR.

For females, mortality in old age was consistently higher in the GDR but, again, children did better than in the FRG. As with males, by the late 1970 s, their advantage was lost. During the 1980 s, mortality in the GDR among men over 15 and women over 40 steadily worsened relative to the FRG. From 1989 to 1990, the relative disadvantage of GDR males became even larger, affecting all age groups, although those aged less than 65 years were affected most (fig 2). Females also experienced a slight worsening, most notably in children. However, after 1993 this differential became smaller, reflecting the improvement in life expectancy in both sexes (fig 1). By 1997 mortality was still higher in the former GDR, with all male age groups except infants and children contributing almost evenly to this gap while female excess mortality was dominated by those over 65 years (fig 2).

\section{PROBABILITY OF DYING BY AGE}

Age specific probabilities of dying are shown in figure 3, with data for Poland added. This shows the relative advantage enjoyed by children in the GDR during the 1970s. For clarity, only four age groups are shown. A detailed analysis revealed that the differential between the GDR and the Federal Republic was present in both infants and children. In 1969-75, the average ratio of rates in the FRG to those in the GDR at age $<1$ year was 1.32 , while the equivalent for age 1-4 was 1.16 (data not shown). From the late 1970s, rates in both 

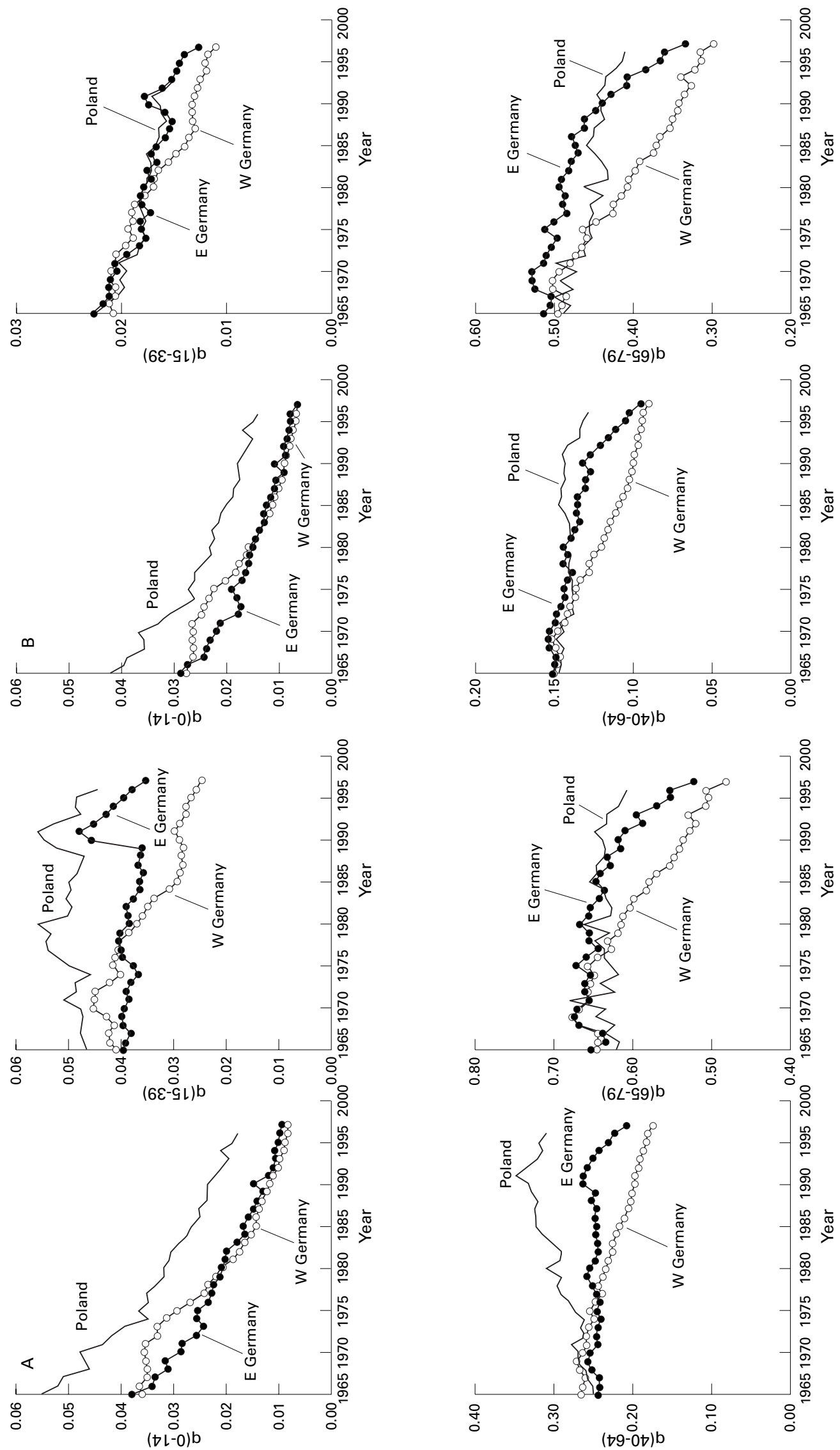

Figure 3 (A) Trends in probabilities of dying for broad age groups in East and West Germany and Poland, men. (B) Trends in probabilities of death for broad age groups in East and West Germany and Poland, women. 
parts of Germany were almost identical although substantially lower than in Poland.

A similar pattern is seen at ages $15-39$, at least for the first part of the period. From 1980, death rates diverged markedly, with rates in the GDR moving closer to those in Poland and, among males, exhibiting a similar peak around 1990, attributable to a transient rise in deaths from injuries. ${ }^{21} 22$

In older age groups, although all countries started from a similar position, trends in the GDR, especially for females, were much closer to those in Poland than to the FRG. Males and females in each country experienced fluctuations in probability of dying during the 1960s and 1970s. In the FRG, this was followed by a continuous decline from the mid-1970s, while the corresponding figures in the GDR did not improve until the mid-1980s. Again, both the GDR and Poland exhibit a peak in probability of dying around 1990, more pronounced in men aged 40-64 although smaller than in young adults. The decline in probability of dying during the 1990s in the former GDR and Poland mirrors improvements in life expectancy shown earlier, but while the figures for
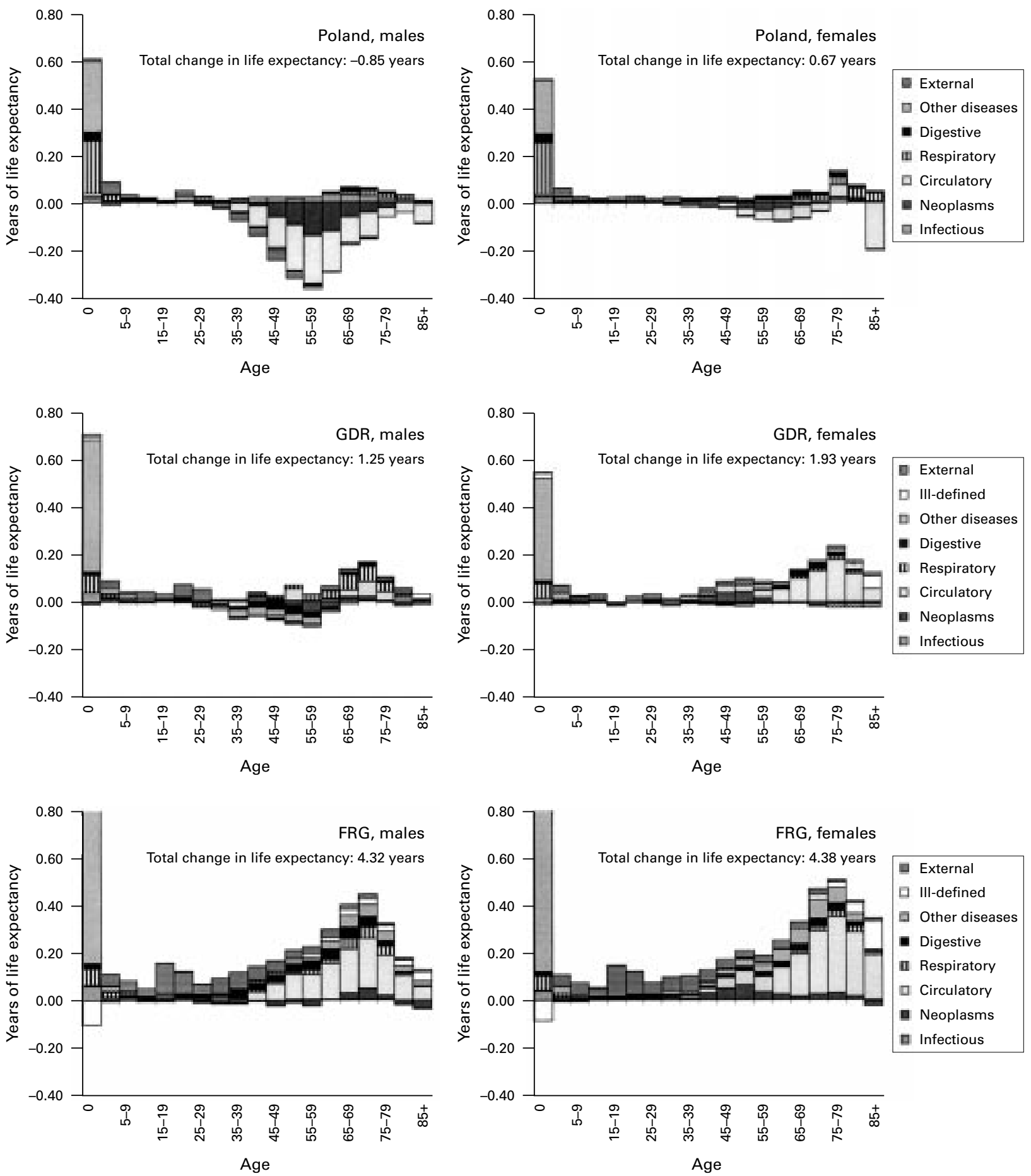

Figure 4 Contribution of age and cause of death to the overall changes in life expectancy at birth between 1974 and 1988-89: Poland, GDR, and FRG. 
KEY POINTS

- In health terms, the former GDR occupied an intermediate position between the east and the west during the communist period.

- Male mortality in the former GDR did not show the worsening seen in Poland, but it did not experience the improvements seen in the old FRG either.

- Female mortality patterns were broadly similar in the GDR and Poland, suggesting the existence of risk factors acting predominantly on men.

men aged 15-39 recovered steadily, they failed to achieve the 1988/89 level until 1996 (fig 3A).

CAUSES OF DEATH

Figure 4 shows how different causes of death contributed to the change in life expectancy in each country between 1974 and 1988/89. In all countries, improvements in infant mortality made large contributions, greatest in the FRG and least in Poland. At other ages the pattern is very different in each country. Taking males first, in the FRG, falling death rates among adults at all ages contributed substantially to improved life expectancy. In contrast, in Poland, death rates have risen at all ages over 35 , most notably in the 50-59 age group. The GDR provides a mixed picture, with little overall change but a small worsening among those under 60 , counterbalanced by improvements among those over 60 . In the FRG, improvements in adult male mortality have been attributable, largely, to falling deaths from cardiovascular disease, with lower deaths from injuries contributing to improvements at younger ages. In Poland, the worsening situation for adults was attributable mostly to higher death rates from cardiovascular disease, with neoplasms a close second. The GDR again shows a very mixed picture, but with smaller changes than in the other countries.

Turning to females, the FRG again shows a marked improvement, attributable largely to lower death rates from cardiovascular disease and less fatal injuries among the young. In Poland, women have done better than men, although this resulted only in stagnation rather than improvement. The GDR again occupies an intermediate position, with improvements attributable to falling deaths from cardiovascular disease among the middle aged and elderly.

\section{Discussion}

DATA QUALITY

Comparisons such as this depend upon the quality and completeness of information on population and deaths. In both parts of Germany each death had to be registered so the data supplied to WHO and United Nations are seen as, officially, virtually complete. The definition of resident population was almost identical, although the method of estimating the population denominator differed slightly. ${ }^{23}$
With the exception of years with unusual population movements such as $1989 / 90$, this is not likely to have had any major effect. Thorough examination of age specific deaths revealed no unusual discontinuities in trends over time, except some fluctuations in male mortality (and, to a lesser extent, female) especially among the elderly in selected years in the 1960s and 1970s in both parts of Germany and in 1985 in the GDR coinciding with influenza epidemics. ${ }^{24}$ The brief increase in probability of dying among the elderly in Poland in 1971 may also be explained by an influenza epidemic reported that year. ${ }^{25}$ The unusual mortality increase in the GDR from 1989 to 1990, however, along with the temporary decline of the east-west mortality differential in 1988 (fig 2), raises questions about registration deficiencies in those years. The huge east-west migration of 1989/90 could have affected observed mortality trends. Assuming, however, that complete registration of westward migration could not be ensured because of the substantial changes in the GDR at this time, it seems more likely that the true mortality rate was underestimated because of overestimation of the population denominator. ${ }^{26}$ As the young and more qualified are more likely to migrate westwards, especially in $1989 / 90,{ }^{27}$ it seems probable that the less healthy were left behind, tending to increase mortality. Although this possibility cannot be excluded, the overall impact may be considered small. A case study in Saxony, in the former GDR, estimated that migration may have affected the decline in life expectancy between 1989 and 1990 by about 3\% in males and $9 \%$ in females. ${ }^{28}$ Little is known, however, about the impact of post-unification east-west and west-east migration. Although, again, selective migration might have influenced mortality among young adults with the majority of migrants being under $50,{ }^{29}$ the impact on mortality among the elderly may reasonably be assumed negligible.

Selective migration has also been discussed with respect to the considerable westward migration of almost 4 million east Germans before the Berlin Wall was built in $1961 .^{29}$ These Flüchtlinge (refugees) were predominantly young and their departure had a negative impact on the age structure in the former GDR. Birth cohort analyses, however, indicate little impact on mortality patterns. ${ }^{30}$

The observed east-west mortality differential may also have been influenced by differences in the definition of live and stillbirths, leading to underestimation of infant mortality in the GDR. It has been estimated that the infant mortality rate for the FRG in 1973 of 22.7 per 1000 live births would have been reduced to 20.2 if the GDR definition were applied. ${ }^{31}$ In this analysis it was shown that the childhood mortality differential was present in both infants and 1-14 year old children suggesting that the GDR advantage in the early 1970s was not attributable simply to registration practices.

Obviously one must also consider variation in coding of causes of death, particularly as the data used span two editions of the ICD and, 
more importantly, against the background of known differences in coding practices between the two parts of Germany. ${ }^{32}$ However, as such differences are more likely to cause comparability problems where more precise categories are used, this paper uses broad diagnostic groups to minimise any effect. Also, comparing temporal changes in mortality by cause in one country with the equivalent changes in the other (fig 4) is less problematic than a direct inter-country comparison.

Turning to data for Poland, available evidence suggests similar problems regarding infant mortality ${ }^{1}$ and cause of death certification to those in the GDR, with deaths from hypertension and atherosclerosis being overestimated at the expense of deaths from ischaemic heart disease and cerebrovascular disease. ${ }^{33}$ Completeness of death registration is considered good, although only fragmentary data were available for the years immediately after the second world war and thus have to be interpreted with caution, particularly with respect to the steep increase in life expectancy between 1950 and 1960 (fig 1). Formal evaluation of the quality of the Polish data is not available, but, with the exception mentioned above, is believed to be satisfactory. ${ }^{22}$

WHY WAS THE GDR DIFFERENT FROM THE WEST? As any difference in registration practices seems minor the advantage enjoyed by the GDR in infant and childhood mortality in the early 1970 s seems genuine and is consistent with what is known about the comprehensive system of maternal, infant and child care in the east. The system included, for example, a highly regulated vaccination schedule for children while in the west vaccination was not obligatory. ${ }^{31}$ This might be reflected in death rates from infectious diseases being up to two times higher in infants and children under 10 in the west in 1974 (data not shown). Also, a fraction of the mortality differential is attributable to external causes as deaths related to motor vehicle accidents in the children under 5 were up to 2.5 times higher in the west, probably reflecting differences in traffic density.

Still, caution is required when interpreting the relative advantage of the GDR in infant mortality in the early 1970 s as birth rates dropped by over $20 \%$ between 1971 and 1973 , apparently attributable to the legalisation of abortion in $1972 .^{31}$ This was accompanied by a $13 \%$ decline in infant mortality. Maternal mortality also declined by almost $50 \%$ until the mid-1970s, which probably contributed to the relative advantage of the GDR regarding deaths among women aged 15-39 years. The corresponding rates in the FRG remained higher until the end of the 1970s. ${ }^{34}$

The subsequent loss of the advantage of the GDR in premature mortality was mainly attributable to a substantial improvement achieved in the west rather than a worsening in the GDR. This supports the view that the GDR system of centralised health care, emphasising integration and prevention, seemed successful as long as services could be based on simple cause-effect models and involved low technol- ogy. With chronic diseases becoming more prevalent, needing much more complex management drawing on increasingly sophisticated technology, the system found it increasingly difficult to meet these challenges. ${ }^{35}$ While in the west social spending increased steadily it remained static in the east. ${ }^{36}$ Shortages became apparent in the GDR during the 1980s, affecting medical equipment, pharmaceuticals, supplies and personnel. This is illustrated by the marked reduction in deaths from testicular cancer in the former GDR when modern chemotherapeutic agents became available after unification. ${ }^{37}$ Other evidence suggests that shortages in surgical capacity may have been related to higher infant mortality from congenital anomalies of the heart and cardiovascular diseases in the GDR compared with the west in the $1980 \mathrm{~s}^{38}$

This conclusion receives support from other evidence of lack of modern medical care. ${ }^{6}$ Available data indicate undertreatment or less effective treatment of hypertension as prevalence rates of treated but uncontrolled hypertension were found to be higher than in the old FRG. ${ }^{39}$ Further evidence suggests possible undertreatment of elderly stroke patients in the former GDR, reflected by a high case fatality among those over $65 .^{40}$ This, along with the observation of general unfavourable conditions for the elderly in the GDR, ${ }^{36}$ may, at least partly, explain the widening mortality differential between the two parts of Germany among those over 65 during the 1980s as well as the relatively small improvement in life expectancy in both sexes over time.

The FRG, on the other hand, experienced a considerable decline in adult mortality since 1975, shown to be attributable, largely, to falling deaths from cardiovascular disease. This mirrors the continuous decline in cerebrovascular deaths since the late 1960s and the accelerating decline in male mortality attributable to myocardial infarction in the FRG since $1980 .^{24}{ }^{41}$ Trends in cardiovascular risk factor levels indicate only little improvement during the $1980 \mathrm{~s}^{42}{ }^{43}$ Thus, a more probable explanation might be improved survival attributable to improvements in access to and quality of acute care and treatment of cardiovascular diseases. ${ }^{44}$ This would be consistent with findings from other industrialised countries that have found a substantial contribution of medical care to the decline of coronary heart disease mortality. ${ }^{45} 46$

Although the mortality differential between both parts of Germany widened progressively since the mid-1970s, infant mortality rates, at least the officially registered, remained quite similar. Elsewhere we have shown that while neonatal mortality improved more steeply at the advantage of the Federal Republic, postneonatal mortality remained continuously lower in the east, ${ }^{47}$ suggesting a probable superiority in the FRG regarding perinatal care while the GDR may have been more effective in managing postneonatal care. Higher postneonatal mortality in the west may, however, also be attributed to a postponement of neonatal deaths into the postneonatal period as suggested by the observation of a shift from 
perinatal mortality to neonatal mortality. ${ }^{48}$ Still, this may explain only a fraction of the pre-unification east-west postneonatal mortality differential.

WHY WAS THE GDR DIFFERENT FROM POLAND? In health terms the GDR has repeatedly been shown as the most advantaged of the Soviet bloc countries. ${ }^{7}$ Compared with Poland, trends over time indicate a substantial advantage regarding a variety of health indicators.

The reason for differences in infant mortality must remain speculative but on the basis of findings from elsewhere, one possibility is that there was better neonatal care in the GDR with advanced medical technology available during the $1980 \mathrm{~s}{ }^{36}$ This is consistent with the finding that poor neonatal care contributed measurably to the relatively high neonatal mortality in Czechoslovakia at this time. ${ }^{49}$ It has, however, to be noted that in the mid-1980s birth rates in Poland were about $40 \%$ higher than in the GDR and this could have contributed to greater scarcity of facilities compared with the GDR.

The worsening of adult male mortality in Poland reflects an almost uninterrupted increase in deaths attributable to cardiovascular diseases and neoplasms since the mid-1960s, only slowing down in the $1980 \mathrm{~s} .{ }^{22}$ In 1980 , the rise of Solidarity and the imposition of martial law led to a marked reduction in alcohol consumption, ${ }^{50}$ which may be an explanation for the sudden decline in deaths in young adults (fig 3A).

A key finding is that, throughout this period, female mortality has been broadly similar in Poland and the GDR whereas that for males has differed, suggesting risk factors acting predominantly on men. While there are several possible candidates, the causes of death most affected suggest life style factors such as smoking and alcohol misuse as particularly important. Others, such as poor nutrition, while not able to be excluded entirely, are unlikely to have differed so much between men and women.

This study provides further evidence of the complexity of the east-west mortality differential emerging in the $1960 \mathrm{~s}$ in Europe. It highlights the intermediate position in health terms the former GDR occupied during much of the communist period. One key finding is that throughout the 1970s and 1980s the GDR did not experience either the worsening in (male) mortality seen in Poland or the improvement seen in the FRG. Many health determinants seem to have played a part. High levels of hypertension in east German men, for example, were suggested as a major determinant of the increasing stroke incidence observed during the 1970 s and 1980 s. $^{40}$ The deteriorating cardiovascular risk factor profile in the east was considered a main reason for the increasing mortality differential between the two parts of Germany after the 1970 s. $^{39}{ }^{51}$ There is, however, increasing evidence that medical care might have been more important for the east-west mortality differential than has been assumed so far. ${ }^{52}$ This is the topic of further research that will be published in due course.
Funding: EN is supported by a European Commission TMR Fellowship, no FMBICT983062.

Conflicts of interest: none.

1 Okolski M. East-West mortality differentials. In: Blum A, Rallu JL, eds. Demographic dynamics. European population, Rallu JL, eds. Demographic dynamics. Europ
vol 2. Paris: John Libbey, 1993:165-89.

2 McKee M, Zatoñski W. How the cardiovascular burden of llness is changing in Eastern Europe. Evidence-based Cardiovascular Medicine 1998;2:39-41.

3 Chenet L, McKee M, Fulop N, et al. Changing life expectancy in central Europe: is there a single reason? $f$ Public Health Med 1996;18:329-36.

4 Bobak M, Skodova Z, Pisa Z, et al. Political changes and trends in cardiovascular risk factors in the Czech Republic, 1985-92. F Epidemiol Community Health 1997;51:272-7.

5 Wasem J. Health care reform in the Federal Republic of Germany: the new and the old Länder. In: Altenstetter C, Björkman JW, eds. Health policy reform, national variations and globalization. London: Macmillan, 1997:161-74.

6 Schott J, Bergmann KE, Wiesner G. Der Lebensverlängerungsproze $\beta$ - ein Vergleich zwischen Westund Ostdeutschland. $Z$ Bevölkerungswissenschaft 1995;20: $187-206$.

7 Eberstadt N. Health and mortality in eastern Europe. Communist Economies 1990;2:347-71.

8 McKee M, Chenet L, Fulop N, et al. Explaining the health divide in Germany: contribution of major causes of death to the difference in life expectancy at birth between east and west. $Z$ Gesundheitswissenschaften 1996;4:214-24.

9 United Nations. Demographic Yearbook. Historical Supplement. New York: United Nations, 1979.

0 Staatliche Zentralverwaltung für Statistik. Statistisches fahrbuch der Deutschen Demokratischen Republik. Vols 1960/61 and 1972. Berlin: Deutscher Zentralverlag Berlin/ Staatsverlag der Deutschen Demokratischen Republik, 1961 and 1972 .

11 http://www.who.int/whosis/mort/download.htm

12 Statistisches Bundesamt. Todesursachenstatistik. Wiesbaden: Statistisches Bundesamt, 1990-1997.

13 Statistisches Bundesamt. Gesundheits- und Sozialwesen in Übersichten. Sonderreihe mit Beiträgen für das Gebiet der ehemaligen DDR. Heft 27. Wiesbaden: Statistisches ehemaligen DDR.

14 Höhn C, Pollard J. Mortality in the two Germanys in 1986 and trends 1976-1986. European f Population 1991;7:1-28. 5 Shkolnikov VM, Meslé F, Vallin J. Health crisis in Russia. Population: an English selection 1996;8:123-90.

16 Chiang CL. The life table and its applications. Florida: Malabar, 1984 .

17 Andreev EM. Metod komponent v analize prodolzjitelnosti zhizni [The component method in analysis of life expectancy]. Vestnik Statistiki 1983;3:42-7.

18 Arriaga E. Measuring and explaining the change in life expectancies. Demography 1984;21:83-96.

19 Pressat R. Contribution des écarts de mortalité par âge à la différence des vies moyennes. Population 1985;40:766-70.

20 Microsoft Corporation. Microsoft Excel Version 97.

21 Wiesner G, Hoffmeister H, Casper G. Imparitäten zwischen Ost und West-einige Besonderheiten der Mortalitätsentwicklung nach der Wiedervereinigung Deutschlands. Bundesgesundheitsblatt 1993;36:464-9.

22 Zatoñski WA, Boyle P. Health transformations in Poland after 1988. F Epidemiol Biostat 1996;4:183-97.

23 Brückner G. Todesursachen1990/91 im vereinten Deutschland. Wirtschaft und Statistik 1993;4:257-78.

24 Casper W, Wiesner G, Bergmann KE, eds. Mortalität und Todesursachen in Deutschland. RKI-Heft 10/1995. Berlin: Robert Koch-Institut, 1995.

25 World Health Organisation. Influenza in the world: October 1971-September 1972. Wkly Epidemiol Rec 1972;47:42952.

26 Häussler B, Hempel E, Reschke P. Die Entwicklung von Lebenserwartung und Sterblichkeit in Ostdeutschland nach der Wende (1989-1992). Gesundheitswesen 1995;57: 365-72.

27 Voigt D, Belitz-Demiriz H, Meck S. Die innerdeutsche Wanderung und der Vereinigungsproze $\beta$. DeutschlandArchiv 1990;23:732-46.

28 Rossa K, Schott J. Berechnung von Sterbetafeln und Trends der Lebensdauermaße für die Sächsische Bevölkerung im Zeitraum 1980 bis 1994. Gesundheitswesen 1997;59:31520.

29 Grünheid E, Schulz R. Bericht 1996 über die demographische Lage in Deutschland. $Z$ Bevölkerungswissenschaft 1996;21:345-439.

30 Dinkel RH. Kohortensterbetafeln für die Geburtsjahrgänge ab 1900 bis 1962 in den beiden Teilen Deutschlands. $Z$ Bevölkerungswissenschaft 1992;18:95-116.

31 Henning A. Mother and child care. In: Light DW, Schuller A, eds. Political values and health care: the German experience. Cambridge, MA: MIT Press, 1986:467-86.

32 Heinemann L, Barth W, Löwel H. Zur Validität der Herz-Kreislauf-Mortalitäts-Statistik der ehemaligen DDR. Z Gesundheitswissenschaften 1998;6:108-19.

33 Cooper R, Schatzkin A, Sempos C. Rising death rates among Polish men. Int f Health Services 1984;14:289-302.

34 United Nations. Demographic Yearbook 1980. Vol 32. New York: United Nations, 1982.

35 Niehoff JU, Schneider F, Wetzstein E. Reflections of the health policy of the former German Democratic Republic. health policy of the former German

36 Knox RA. Germany: One nation with health care for all. New York: Faulkner and Gray, 1993 
37 Becker N, Boyle P. Decline in mortality from testicular cancer in West Germany after reunification. Lancet 1997:350 744 .

38 Bundesminister für Gesundheit, ed. Indikatoren zum Gesundheitszustand der Bevölkerung in der ehemaligen DDR. Baden-Baden: Nomos-Verlagsgesellschaft, 1993.

39 Heinemann L, Greiser EM. Blood pressure, hypertension, and other risk factors in East and West Germany. Ann Epidemiol 1993;3 (suppl):S90-5.

40 Eisenblätter D, Claßen E, Schädlich $\mathrm{H}$, et al. Häufigkeit und Prognose von Schlaganfallerkrankungen in der Bevölkerung Ostdeutschlands. Ergebnisse von Schlaganfallregistern in den Jahren 1985-1988. Nervenarzt 1994;65:95100 .

41 Statistisches Bundesamt, ed. Gesundheitsbericht für Deutsch land 1998. Stuttgart: Metzler-Poeschel, 1998.

42 Hoffmeister H, Mensink GBM, Stolzenberg H. National trends in risk factors for cardiovascular disease in trends in risk factors for cardiovasc

43 Laaser U, Lemke-Goliasch P, Schumann V, et al. Behandlung und Kontrolle primärer kardiovaskulärer Risikofaktoren in den alten Bundesländern. Ergebnisse des betoren in den alten Bundesländern. Ergebnisse des bevölkerungsmedizinischen Monitoring durch die Nationalen
Gesundheitssurveys der DHP 1984/85-1988-1990/91. Z Gesundheitssurveys der DHP 1984/85-1.

44 Herman B, Stüdemann G, Greiser E. Trends in acute myocardial infarction mortality, morbidity, and medical care in the city of Bremen. Ann Epidemiol 1993;3 (suppl):S62-8.
45 Bots ML, Grobee, DE. Decline of coronary heart disease mortality in The Netherlands from 1978 to 1985: contribution of medical care and changes over time in presence of major cardi Risk 1996,3:271-6.

46 Capewell S, Morrison CE, McMurrey JJ. Contribution of modern cardiovascular treatment and risk factor changes to the decline in coronary heart disease mortality in Scotland between 1975 and 1994. Heart 1999,81:380-6.

47 Nolte E, Brand A, Koupilova I, et al. Neonatal and postneonatal mortality in Germany since unification. 7 Epidemiol Community Health 2000;54:84-90.

48 Cartlidge PHT, Stewart JH. Effect of changing the stillbirth definition on evaluation of perinatal mortality rates. Lancet 1995;346:486-8.

49 Koupilová I, McKee M, Holcik J. Neonatal mortality in the Czech Republic during the transition. Health Policy 1998;46:43-52.

50 Varasovszky Z, Bain C, McKee M. Alcohol related mortality in Poland and Hungary: differences and similarities. $\mathcal{F}$ Epidemiol Community Health 1997;51:167-71.

51 Heinemann L, Dinkel R, Görtler E. Life expectancy in Germany: Possible reasons for the increasing gap between east and west Germany. Rev Environ Health 1996,11:15-26. 52 Velkova A, Wolleswinkel-van den Bosch JH, Mackenbach JP. The east-west life expectancy gap: Differences in mortality from conditions amenable to medical intervention. Int $\mathcal{F}$ Epidemiol 1997;26:75-84. 